\title{
Avaliação da viabilidade de microrganismos probióticos incorporados em ração de truta-arco-íris (Oncorhynchus mykiss)
}

\author{
[Evaluation of the viability of probiotic microorganisms impregnated \\ into rainbow trout (Oncorhynchus mykiss) ration]
}

\author{
D.E. Torres, I.M. Mancilha*
}

Escola de Engenharia de Lorena - Universidade de São Paulo - Lorena, SP

\section{RESUMO}

A produção aquícola mundial tem demandado estudos que buscam soluções para os problemas produtivos e sanitários apresentados na piscicultura. Nesse contexto, o uso de produtos probióticos demonstra ser uma abordagem promissora. Dessa forma, o presente trabalho teve como objetivo avaliar a viabilidade de um pool de cepas de Lactobacillus incorporados à ração de truta-arco-íris. Para tanto, as respectivas cepas foram previamente cultivadas em caldo MRS e submetidas à criocentrifugação. As células obtidas foram ressuspensas em soro fisiológico acrescentado de $2 \%$ de óleo de soja, sendo posteriormente incorporadas à ração por meio de misturador circular. Essa ração foi devidamente armazenada sob refrigeração a $4^{\circ} \mathrm{C}$, por 120 dias, sendo retiradas aleatoriamente três amostras, a cada 15 dias, para avaliação da viabilidade das bactérias, por meio da contagem em placas. Os resultados demonstraram que houve uma redução não significativa $(\mathrm{P}>0,05)$ na população de células viáveis, correspondente a $2 \%$, após 30 dias de armazenamento. Verificou-se também, após esse período, uma população aproximada equivalente a 3,00 x $10^{8} \mathrm{UFC} / \mathrm{g}$. Dessa forma, demonstrou-se a possibilidade de desenvolvimento de formulações probióticas por meio da incorporação de cepas específicas em rações de trutas, o que poderá contribuir para o desenvolvimento de tecnologias alternativas para produção de peixes.

Palavras-chave: probióticos, Lactobacillus, truta-arco-íris

\begin{abstract}
Among the exotic species of fish produced in Brazil, the rainbow trout (Oncorhynchus mykiss) has been highlighted during the past few years. The expansion of this sector has been intensifying the need for further studies in order to decrease production and health problems presented in aquaculture, as well as to develop alternative technics to controversial antimicrobial treatments. In this context, the use of probiotics has been shown to be a promising approach to the improvement in trout husbandry. Thus, the present study aimed to contribute to the development of an alternative technology in the rainbow trout husbandry by evaluating the effect of probiotic preparations on the performance of the animals subjected to conventional husbandry conditions or chronic stress. Therefore, in this paper we report the results regarding the evaluation of the viability of a pool of 4 Lactobacillus probiotic strains incorporated into rainbow trout ration using soybean oil as vehicle. The results have demonstrated a high efficacy of cell incorporation into the ration with high viability rate after storage for 120 days at $4^{\circ} \mathrm{C}$.
\end{abstract}

Keywords: probiotics. Lactobacillus, rainbow trout

\section{INTRODUÇÃO}

A aquicultura é a atividade zootécnica que mais cresce no âmbito da produção de alimentos de origem animal, o que poderá colocar esse setor à frente dos demais, gerando renda, emprego e fontes proteicas de qualidade para a população (El estado..., 2012).

Recebido em 14 de dezembro de 2018

Aceito em 17 de outubro de 2019

*Autor para correspondência (corresponding author)

E-mail: mancilha@usp.br 
Dentre as espécies exóticas de peixes produzidas no Brasil, a truta-arco-íris tem se destacado. A truta-arco-íris (Oncorhynchus mykiss - Walbaum, 1792) é originária dos rios da vertente Pacífica da América do Norte, pertence à ordem Salmoniformes, família Salmonidae, sendo a espécie de peixe de águas frias mais difundida nos diferentes países (Hershberger, 1992). É considerado um peixe nobre, de sabor delicado e de excelentes qualidades nutricionais, visto que apresenta elevado teor proteico, vitaminas, sais minerais, além de ser fonte de $\Omega-3$ (ômega 3) e outros ácidos graxos insaturados responsáveis pela redução dos níveis de colesterol no sangue (Nutrition Data, 2013). A truta-arco-íris destacase pelo apreciado sabor e qualidade nutricional de sua carne, tendo sido introduzida na década de 1940, aclimatando-se perfeitamente nas águas frias de regiões serranas do sudeste e sul no Brasil. O pleno conhecimento de seu manejo, sua adaptabilidade em regiões não exploradas pela piscicultura, bem como o alto valor agregado a sua carne e derivados, fomentaram grande interesse em sua produção em nível nacional, a qual exibiu aumento de $29,3 \%$ no triênio 2008 2010 (Brasil, 2012).

O desenvolvimento da aquicultura tem sido acompanhado de um significativo aumento da proliferação de doenças, principalmente bacterianas. Tais enfermidades aumentam proporcionalmente com o aumento da densidade de animais nos tanques manejados intensivamente. A sanidade das criações também é comprometida pela má qualidade e pela quantidade dos alimentos fornecidos, o que afeta a qualidade da água devido à elevada produção de resíduos pelos animais. A má qualidade da água provoca estresse e afeta o sistema imunológico dos animais, predispondo-os ao surgimento de doenças oportunistas. Problemas sanitários comprometem o desempenho zootécnico, geram altas taxas de mortalidade e levam a prejuízos para a produção (Leira et al., 2017).

O aumento das doenças bacterianas e a busca por uma melhoria na produtividade desencadeiam o uso indiscriminado de antimicrobianos como medida profilática ou como promotores de crescimento. Esse procedimento pode acarretar o surgimento de espécies de microrganismos patogênicos multirresistentes, por pressão seletiva, que favorece as mutações resistentes e o fluxo horizontal de genes de resistência por plasmídeos. Além disso, existe o risco de essa resistência ser transmitida às espécies nativas e aumentar a quantidade de resíduos na carne e em seus derivados. Somado à questão da sanidade, existe também a dificuldade de se conquistar o comércio exterior, pois o uso de promotores de crescimento e antimicrobianos como medida profilática tem provocado recusa à importação de alimentos. Tal medida pode ser verificada na moratória adotada pela União Europeia no tocante à proibição da incorporação de antibióticos como promotores de crescimento na alimentação animal (Parlamento Europeu, 2003).

Diante do desafio de aperfeiçoar a produtividade aquícola, com efeitos igualmente benéficos sobre o ambiente e a saúde humana, faz-se necessário o desenvolvimento de tecnologias sustentáveis que assegurem uma abordagem ecossistêmica no uso de recursos naturais e uma estabilidade econômica.

As pesquisas concentram-se em combater doenças, a fim de atingir desempenho zootécnico satisfatório e diminuir a dependência aos antimicrobianos. Dentre essas, destacam-se as técnicas de biorremediação, o uso de vacinas e compostos imunoestimulantes, além de alimentos funcionais, como prebióticos e probióticos. Nesse contexto, os benefícios conferidos pelos microrganismos probióticos, cujos principais mecanismos de ação se baseiam na modulação da microbiota do trato gastrointestinal e no estímulo à resposta imune, correspondem a uma nova abordagem na piscicultura e têm sido demonstrados como uma alternativa promissora na produção aquícola. A incorporação de espécies de microrganismos probióticos na ração de peixes tem provocado melhorias na conversão alimentar, desempenhando função terapêutica, profilática e promotora de crescimento. Além disso, esse procedimento pode contribuir para mudanças positivas no perfil microbiológico do ambiente de criação, com redução do surgimento de doenças oportunistas, o que favorece as condições sanitárias da criação (Moriarty, 1997).

Contudo, os benefícios das preparações probióticas dependem de uma série de fatores, como a espécie do microrganismo, a forma de veiculação, a frequência do tratamento e a espécie animal submetida ao tratamento. Dessa forma, novos estudos são necessários, tendo em vista a avaliação de efeitos de diferentes cepas de 
microrganismos probióticos sobre as várias espécies de peixes exploradas comercialmente, visando contribuir para padronização sustentável da produtividade aquícola. Desse modo, o presente trabalho buscou contribuir para o desenvolvimento de uma tecnologia alternativa na criação de truta-arco-íris, ao avaliar o efeito de preparações probióticas sobre o desempenho dos animais submetidos às condições convencionais de manejo e de estresse crônico Assim, especificamente esta etapa do trabalho teve como objetivo avaliar a viabilidade de cepas de Lactobacillus devidamente incorporadas em ração extrusada de trutas. Vale destacar que parte desses resultados foram parcialmente publicados como resumo expandido no XX Sinaferm - 2015.

\section{MATERIAL E MÉTODOS}

Os experimentos foram conduzidos no Laboratório de Probióticos da Escola de Engenharia de Lorena - EEL - USP e na Estação Experimental de Salmonicultura "Ascânio de Faria”, em Campos do Jordão, SP. Foram avaliadas quatro cepas de Lactobacillus, na forma de um "pool", constituído por L. plantarum ATCC 8014, L. acidophillus ATCC 4356, L. fermentum ATCC 9338 e L. casei ATCC 7469, adquiridas da coleção de culturas da Fundação André Tosello de Pesquisa e Tecnologia, Campinas, SP.

A formulação da preparação probiótica constituída do referido "pool" de Lactobacillus foi conduzida de acordo com metodologia descrita por Coutinho (2012), sendo as respectivas cepas ativadas individualmente a $37^{\circ} \mathrm{C} / 48 \mathrm{~h}$, por meio de repiques sucessivos em tubos de ensaio e, finalmente, em tubo de centrífuga com capacidade de 1 litro (Beckman J6-HC), contendo 600mL de caldo MRS, pH 6,2, esterilizado a $121^{\circ} \mathrm{C}$ por $20 \mathrm{~min}$. As suspensões de células obtidas foram centrifugadas a 4785 x g / 30 minutos, sendo os sobrenadantes descartados por sucção, e as células ressuspensas em 10mL de solução fisiológica, seguindo-se a homogeneização com auxílio de vórtex. As suspensões resultantes foram devidamente caracterizadas quanto ao número de células pela análise espectrofotométrica da densidade óptica (D.O.). Alíquotas de cada suspensão, contendo o mesmo número de células, foram juntadas para se produzir o "pool" de Lactobacillus contendo 4 × $10^{10} \mathrm{UFC} / \mathrm{mL}$.
O procedimento para incorporação do "pool” de células probióticas na ração foi conduzido em conformidade com o descrito por Gonçalves (2009) e Nakandakare (2010), com modificações, por se tratar de células não liofilizadas. Para tanto, utilizou-se uma ração comercial extrusada específica para peixes carnívoros, em grãos de $6 \mathrm{~mm}$, com $40 \%$ de proteína bruta. Para cada quilograma de ração, foram incorporados $10 \mathrm{~mL}$ do "pool" de células contendo 4 x $10^{10} \mathrm{UFC} / \mathrm{mL}$, utilizando-se como veículo $20 \mathrm{~mL}$ de óleo de soja, a fim de garantir melhor homogeneidade e aderência das células ao grão de ração. A preparação probiótica, assim obtida, foi incorporada à ração com o auxílio de um misturador circular tipo betoneira, e a ração impregnada foi armazenada, sob refrigeração a $4^{\circ} \mathrm{C}$, em sacos plásticos.

A viabilidade das células das respectivas cepas probióticas foi avaliada de acordo com a metodologia descrita por Corrêa-Júnior et al. (2009), após sete, 15, 30, 45, 60 e 120 dias de armazenamento. $\mathrm{O}$ delineamento experimental foi inteiramente ao acaso, composto por um tratamento e três repetições. Para tanto, uma porção representativa da ração, amostrada aleatoriamente de três sacos diferentes, foi suspensa em solução salina estéril a $0,9 \%$, na proporção de $1 \mathrm{~g}$ de ração para $9 \mathrm{~mL}$ de solução salina. Após homogeneização em vórtex por cino minutos, foram preparadas diluições seriadas para plaqueamento pelo método de pour plate em ágar MRS. As placas foram incubadas aerobicamente por dois dias a $37^{\circ} \mathrm{C}$, para posterior contagem de colônias (UFC/g ração), sendo realizadas três repetições. Foi também utilizada uma amostra de ração adicionada apenas de solução salina esterilizada e óleo de soja para respectivo controle. Análises posteriores realizadas foram a observação do aspecto das colônias e a identificação pelo método de Gram e pelo teste de catalase.

A análise dos dados foi feita pelo software Action (complemento do Microsoft Excel). Os dados foram submetidos a teste de normalidade. As médias da contagem de UFC/g de ração foram estatisticamente submetidas à análise de variância (ANOVA) e ao teste de Tukey ao nível de $5 \%$ de significância. 


\section{RESULTADOS}

No presente trabalho, avaliou-se a incorporação de quatro cepas de Lactobacillus, que apresentam propriedades probióticas comprovadas em animais domésticos (Teixeira, 2011, 2017; Coutinho, 2012; Freitas, 2011; Coelho, 2010; Pereira, 2006), na ração de truta-arco-íris, tendo como resposta a população celular ao longo de 120 dias de armazenamento (Fig. 1).

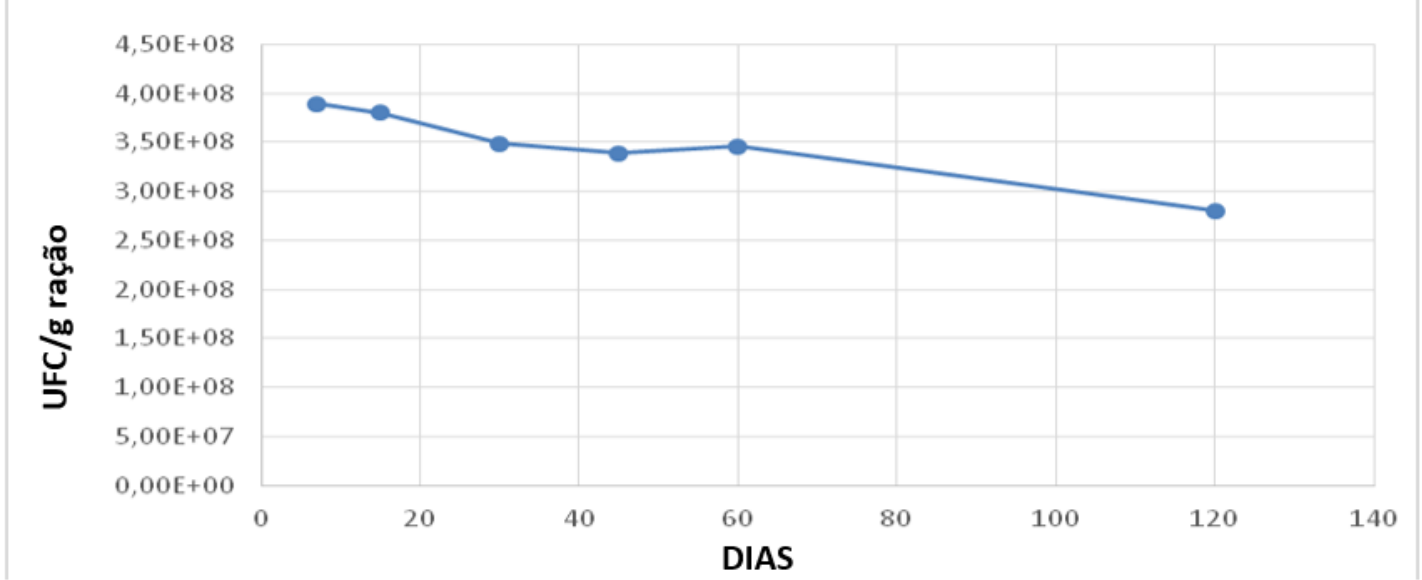

Figura 1. Variação da população das cepas probióticas incorporadas na ração.

\section{DISCUSSÃO}

O termo probiótico é construído a partir do latim $P R O$ (para) e do grego BIOS (vida). Em 2001, a FAO/WHO definiu probióticos como "microrganismos vivos que, quando administrados em quantidades adequadas, conferem efeito benéfico à saúde do hospedeiro". Nesse contexto, vale destacar que esse hospedeiro compreende seres humanos, animais e vegetais, onde o referido efeito benéfico é resultante de atividades específicas dos microrganismos probióticos por meio de diferentes mecanismos de ação. Dentre esses, destacam-se a exclusão competitiva (competição por nutrientes e sítios de adesão), produção de metabólitos (ácidos orgânicos de cadeia curta, vitaminas, bacteriocinas e outros), estimulação do sistema imunológico, etc. Os microrganismos probióticos são disponibilizados no mercado nas formas de preparações líquida, em pó (sachê, encapsulado e comprimido), incorporados em alimentos, em ração animal e nas culturas lácticas liofilizadas. São encontrados também nos inoculantes constituídos de microrganismos endofíticos empregados no cultivo das principais culturas vegetais (Azevedo, 1998; Kumar et al., 2017), bem como no processo de ensilagem de diferentes forrageiras para alimentação animal.

Para que os microrganismos probióticos alcancem sua funcionalidade, é necessário que esses atendam a uma série de requisitos, sendo os principais a viabilidade e o número de células Nesse contexto, no presente trabalho, as respectivas cepas probióticas foram devidamente incorporadas na ração de truta-arco-íris e foi observada uma redução, não significativa ( $\mathrm{P}>0,05)$, na população de células, correspondente a 2,0\%, após 30 dias de armazenamento, mantendo-se uma população aproximada de 3,00 x $10^{8} \mathrm{UFC} / \mathrm{g}$. Essa concentração celular atende satisfatoriamente a um dos critérios que caracterizam uma boa preparação probiótica. Segundo Saad (2006), a dose diária para humanos para se usufruir do valor terapêutico de uma preparação probiótica equivale a $10^{6}$ a $10^{9} \mathrm{UFC} / \mathrm{g}$ do alimento.

Nota-se ainda (Fig. 1) que, após 120 dias de armazenamento da ração contendo a preparação probiótica, foi possível verificar uma população média de células viáveis de $2,80 \times 10^{8} \mathrm{UFC} / \mathrm{g}$, o que corresponde a um decréscimo, não significativo $(\mathrm{P}>0,05)$, de $1,09 \times 10^{8} \mathrm{UFC} / \mathrm{g}$, equivalente a uma redução de $28 \%$ em relação à população inicial de Lactobacillus. Esses valores estão compatíveis com os reportados por CorrêaJúnior et al. (2009), que demonstraram que o óleo de soja é eficaz como veículo para a incorporação, em nível artesanal, de cepas probióticas liofilizadas à ração de peixes, garantindo a manutenção de uma boa viabilidade. 


\section{CONCLUSÕES}

Os resultados obtidos permitem constatar a eficácia do método de incorporação de cepas probióticas na ração de trutas utilizando-se óleo de soja como veículo, o que permitiu a manutenção satisfatória da viabilidade e da população celular ao longo do período de 120 dias de armazenamento.

\section{REFERÊNCIAS}

AZEVEDO, J.L. Ecologia Microbiana. In: Microrganismos endofíticos. Goiânia: Empresa Brasileira de Pesquisa Agropecuária, 1998. Cap.4, p.117-137.

BRASIL. Ministério da Pesca e Aquicultura. Boletim Estatístico da Pesca e da Aquicultura. Brasília: MPA, 2012. 60p.

COELHO, M.D.G. Avaliação do uso de probióticos no combate a infecção causada por Ancylostomidae em cães naturalmente infectados. 2010. 20f. Tese (Doutorado em Ciências) - Escola de Engenharia de Lorena, Universidade de São Paulo, Lorena, SP.

CORREAA-JUNIOR, L.; DIAS, D.C.; TACHIBANA, L.; RANZANI-PAIVA, M.J.T. Incorporação artesanal de probiótico na ração comercial. 2009. Disponível em: <http://www.pesca.sp.gov.br/9recip>. Acessado em: 13 mai. 2014.

COUTINHO, T.S. Avaliação do efeito de microrganismos probióticos sobre a sanidade de bezerros desmamados e bezerras em fase de aleitamento. 2012. 140f. Tese (Doutorado em Biotecnologia Industrial) - Escola de Engenharia de Lorena, Universidade de São Paulo, Lorena, SP.

EL ESTADO mundial de la pesca y la acuicultura 2012. Roma: FAO, 2012. 231p. Disponíble en: <www.fao.org/icatalog/inter-e.htm>. Acceso en 17 enero 2013.
FREITAS, W.L.C. Estudo do efeito de microrganismos probióticos sobre Eimeria acervulina (Tyzzer, 1929) em frangos de corte. 2011. 75f. Dissertação (Mestrado em Ciências) Escola de Engenharia de Lorena, Universidade de São Paulo, Lorena, SP.

GONÇALVES, A. Hematologia e macrófagos policariontes em Colossoma macropomum, mantidos em duas densidades de estocagem, alimentados com dieta contendo probiótico $e$ espirulina. 2009. 65f. Tese (Doutorado em Aquicltura) - Centro de Aquicultura da UNESP Paulista, Universidade Estadual "Júlio de Mesquita Filho" Jaboticabal, SP.

HERSHBERGER, W. Genetic variability in rainbow trout populations. Aquaculture, v.100, p.51-71, 1992.

KUMAR, V.; KUMAR, M.; SHARMA, S.; PRASAD, R. Probiotic and plant health. [s.1.]: Springer. 2017. 537p. (eBook).

LEIRA, M.H.; REGHIM, L.S.; CIACCI, L. S. et al. Problemas sanitários das pisciculturas brasileiras. Pubvet, v.11, p.538-544, 2017.

MORIARTY, D.J.W. The role of microorganisms in aquaculture ponds. Aquaculture, v.151, p.333349, 1997.

NAKANDAKARE, I.B. Inclusão de probióticos no processamento de ração para tilápia do nilo, Oreochromis niloticus variedade GIFT. 2010. 74f. Dissertação (Mestrado em Aquicultura e Pesca) - Instituto de pesca, São Paulo, SP.

NUTRITION Data. Informação nutricional da carne de truta. 2013. Disponível em $<$ http://nutritiondata.self.com/facts/finfish-andshellfish-products/4142/2>. Acessado em: 05 jun. 2013.

PARLAMENTO EUROPEU. Regulamento (CE) N. ${ }^{\circ} 1831 / 2003$ do Parlamento Europeu e do Conselho de 22 de Setembro de 2003, relativo aos aditivos destinados à alimentação animal. Disponível em: <http://eurex.europa.eu/LexUriServ/LexUriServ.do?uri=CE LEX:32003R1831:en:NOT>. Acessado em: 17 jan. 2013. 
PEREIRA, C.A.S. Avaliação do efeito de microrganismos probióticos sobre Eimeria spp. em Rattus norvegicus. 2006. 81f. Tese (Doutorado em Biotecnologia Industrial) Escola de Engenharia Química de Lorena, Universidade de São Paulo, SP.

SAAD, S.M.I. Probióticos e prebióticos: o estado da arte. Braz. J. Pharm. Sci., v.42, p.1-16, 2006.

TEIXEIRA, R.S. Avaliação do efeito de microorganismos probióticos sobre Haemonchus contortus em ovinos. 2011. 79f. Dissertação (Mestrado em Ciências) - Escola de Engenharia de Lorena, Universidade de São Paulo, LorenaSP.
TEIXEIRA, R.S. Avaliação do efeito imunomodulador e carrapaticida de microorganismos probióticos em bovinos da raça Girolando. 2017. 104f. Tese (Doutorado em Ciências) - Escola de Engenharia de Lorena, Universidade de São Paulo, Lorena-SP. 